\title{
Medical Students' Perceptions of the Medical Education Learning Environment at the University of Nairobi: II. A Qualitative Study
}

\author{
Daniel Ojuka, ${ }^{1}$ Faith Aseta, ${ }^{2}$ Beth Githambo, ${ }^{2}$ Brian Wambua ${ }^{2}$ \\ ${ }^{1}$ Department of Surgery, University of Nairobi \\ ${ }^{2}$ School of Medicine, University of Nairobi
}

Correspondence to: Dr. Daniel Ojuka; email: danielojuka@gmail.com

Received: 25 November 2019; Revised: 09 September 2020; Accepted: 10 November 2020; Available online:20 December 2020

\begin{abstract}
Background: The educational environment (EE) has a significant influence on effective student learning. The Dundee Ready Education Environment Measure (DREEM) is a validated tool to assess the EE. A DREEM survey done in early 2019 among medical students at the University of Nairobi highlighted many problems. It was therefore important to explore why such perceptions existed among the medical students. Objectives: To explore medical students' perceptions of the medical education learning environment at the University of Nairobi. Methods: Qualitative focus group discussions (FGD) were held among medical students in years III to VI in groups of between 8and 12 students. The discussions were recorded using a Samsung J6 phone voice recorder, transcribed, coded, and analysed for themes until saturation was reached. Results: We held six FGD with medical students in
\end{abstract}

years III to VI and identified four thematic areas: 1) poor educational infrastructure, 2) poor educational structure, 3) teacher-centred teaching, and 4) lack of social support for students in difficulties. Conclusion: Exploring the perceptions of the EE confirmed students have a poor view of the educational environment. The issues raised are good feedback on teaching, governance and the social culture of the institution.

Keywords: Learning environment, DREEM, Medical students, Qualitative methods

Ann Afr Surg. $2021 ; 18(2)$ : 103-108

DOI : http://dx.doi.org/10.4314/aas.v18i2.8

Conflicts of Interest: None

Funding: None

(C) 2021 Author. This work is licensed under the Creative Commons Attribution 4.0 International License

\section{Introduction}

An educational environment is a combination of the curriculum, infrastructure, administrative structure, and the personalities of teachers and students (1). The experiences the students have of these factors affect the quality of learning (2). The Dundee Ready Education Environment Measure (DREEM) is an internationally validated instrument for evaluating the learning environment of medical education and outlines the strengths and weaknesses of institutions based on students' perceptions (3). High scores indicate a good perception of the environment and low scores a poor or problematic environment. Central to the learning environment is the curriculum; a traditional curriculum has been found to be associated with low scores (4-8). Other factors include authoritarianism by teachers, and students in their final clinical classes who seem to always score low marks for unknown reasons $(6,7)$. DREEM has been used to improve the quality of the surgical environment through reflecting on its outcomes $(9,10)$. In improving quality, the reasoning of the responses received should be explored to understand and increase students' achievement, happiness, motivation, and success. This is done to improve the learning 
environment without compromising standards, through feedback.

DREEM is one of the validated, culturally non-specific tools used to measure medical education environments to demonstrate the weaknesses or strengths of an institution $(9,10)$. A survey done recently at the University of Nairobi's School of Medicine (11) had a score of 96/200, implying a weakness in the learning environment. We sought to explore the factors that contributed to this negative perception by students.

\section{Students and methods}

After obtaining ethical approval from Kenyatta National Hospital-University of Nairobi Ethics and Research Committee (P55/01/2019), focus group discussions (FGD) of $8-12$ students were held in the principal researcher's office for 45-60 min, using guiding questions by the principal researcher together with the co-investigators. The guiding question was: "The DREEM survey showed more negative perceptions than positive. What could be the reasons?' The study population were medical students in years 3 to 6 , who consented in writing to be interviewed. Purposive sampling was used to recruit the students in stratification according to year of study until each group had 8-12 members. Six FGD were held in total. Individual were recruited into group for interview until themes were saturated. Interview conversations were recorded using a Samsung J6 phone recorder. All interviews were held in the presence of the three researchers: BG, FA, and OD.

Next, the three researchers discussed the interviews to agree on the codes and themes emerging, and memos were written on the same. The voice recorders were shared among the three investigators to listen to for a second time and confirm the content after being transcribed for a member check by the investigators. After transcription, the notes were coded and entered into ATLAS. Ti (ATLAS.ti Scientific Software Development $\mathrm{GmbH}$; Berlin, Germany) for analysis into themes.

\section{Results}

Six FGD were held: one with 5thyear students, two with 4 thyears, two with 6thyears, and one with 3rdyears. Four themes were elicited from the interviews.

\section{Poor or lack of learning infrastructure}

The students indicated that whereas the number of students had tripled since 2005, the infrastructure has remained the same. Infrastructure includes classrooms, wards, the library, and accommodation. Some students feel they need to arrive early for class while another class is going on in order to get a place to sit, while others are forced to sit and listen from outside the classroom.

"The discussion venues are not available, so we discuss in the open. The library where we may go to read has a leaking roof. Furthermore, we do not have whiteboards and newer materials for learning. The projections boards and the speaker only work for some professors." FGD Year VI

The number of students is high in the practical area, leading to inadequate exposure, scheduling for practical skills for logbook work becomes difficult, and students cheating on their logbooks.

"I don't know what goes behind deciding the numbers of students. They do not match capacity. If we cannot reduce, we should increase the number of teachers, increase capacity of lecture halls and wards because it frustrates a lot of people." FGD Year III

\section{Teacher-Centered learning process}

Indications were that the learning process does not prepare students well for their profession because it is teacher centered and teachers teach by shaming students, are authoritarian and easily irritated by questions from students. The interaction with patients, which should be a role modeling exercise, is limited as the teachers only talk to the registrar and not to the patients during the rounds. Also, there are no clear objectives for clinical areas. 
Table 1: Codes and themes

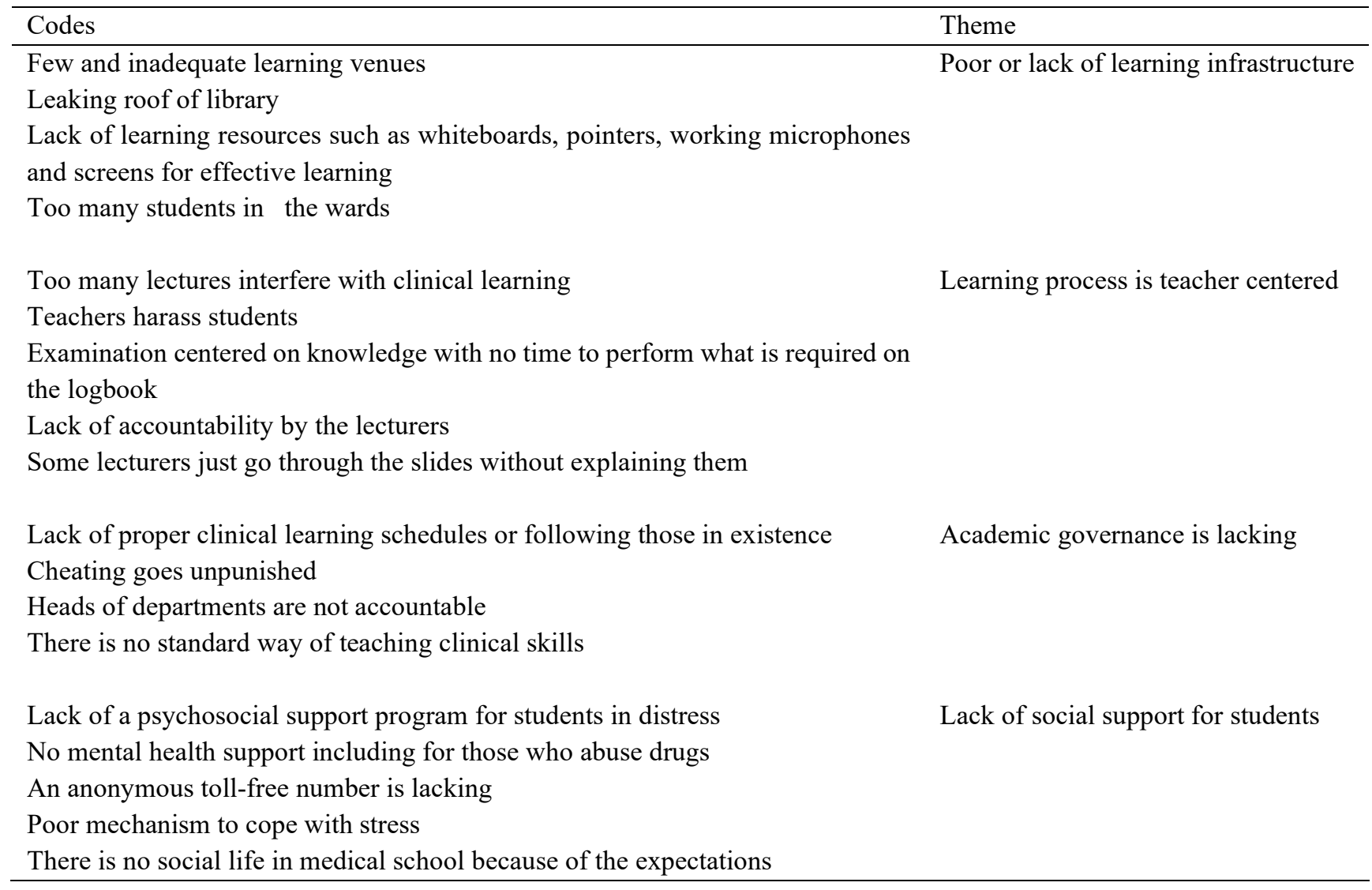

"There is not enough interaction between learner and teachers because of numbers, it cannot be personalized, and so it is more teacher centered." FGD Year IV

"Lecturers do not interact very much with the patient; they just listen story from the registrars. We expect them to interact well so that we learn from them, but in the ward round, I usually put myself in the patient's shoe and feel ignored." FGD Year IV

However, classes with smaller groups, such as the 5th year students, said that having smaller classes with modular teaching before advancing to the clinical areas is beneficial.

"In general, tutorials are better than large classes, they increase people confidence and presentation skills. The only tutorial I have ever enjoyed involved a situation where everyone was given a question and they were to answer." FGD Year V

\section{Academic governance is lacking}

Students said that the schedules are not justifiable given year III has more academic weeks, when they hardly know anything, than year IV, when they are meant to focus on learning clinical skills. Emphasis is more on marks and exams than on learning practical skills, the students can cheat without any consequences, and clinical areas do not have clear objectives.

"I also have another problem with scheduling. In third year, we have 11 weeks and in fourth year the clinical rotation is reduced from 11 to 6 weeks. The fourth year is the foundation year for all the principles. When you go to the final year, they will tell you should have been taught these things in fourth year. They also give you a big logbook, you are expected to know where lumbar puncture is being done, where bone marrow is being done, expected to have gained techniques in physical examination, to go to casualty to fill your logbook. You are not doing them to gain skills but so that you can pass 
the logbook. The scheduling of things is not practical." FGD Year VI

Although teachers are knowledgeable, they may not know how to teach and some miss lectures without any consequences to them. This could be sorted out, in the opinion of students, by having clear academic governance.

"I do not know whether we have a department of medical education, it is a regulation by the World Federation of Medical Education. It oversees the curriculum of teaching in the medical school. The department is aimed at solving the problems in curriculum and teaching... That department would now be able to solve most of these issues, because it seems the evaluation, they give us at the end of the year is not analyzed because they should be giving us feedback and make it public. We need to understand what is going on, who is the lecturer that is missing lectures and what is being done." FGD Year V

Students find the classes that are taught in small numbers such as in year $\mathrm{V}$ where students are given lecturers before they have had adequate time to acquire the relevant skills in clinical areas more conducive to learn than where they have to attend other classes in tandem with attending clinical areas, although they still find it difficult to find time for logbook skills.

"Smaller group tutorials help build confidence, especially in fifth year where you have modular classes then have time in clinical areas." FGD Year V

\section{Lack of social support for students}

The students said that the wards are stressful because teachers ridicule and shame them even when some students care for patients who later die and they are required to do postmortems for the first time. The high expectations placed on them in terms of the skills they are meant to acquire and the lack of time to take part in meaningful extracurricular activities causes stress and leads to drug abuse among students. Consequently, these situations cause mental issues with no structured support in place for these consequences.

"We are stressed all the time, but we are not aware of any system that helps those in stress. $90 \%$ of us are having mental issues-sometimes you are not motivated, having unsettled mind that frustrates you and sometimes it is major, and one ends up contemplating suicide. Almost everyone around me I know is going through psychological problems whether or not they say it. The system is waiting for big cases, but they should publicize these things. ... Also, we should be taught how to deal with the death of our patients. You spend a lot of time clerking and when the patient dies you become sad, but the consultant will just tell you it will be well." FGD Year VI

\section{Discussion}

The DREEM instrument was used to measure the educational environment and identify problem areas in the education program. Having identified these problems, we needed to find out why they occur.

An overall score of below 100/200 has been found in studies from the Asian and Arab worlds and is mainly associated with the use of a traditional curriculum rather thana modern one that includes problem-based learning or system-based learning (6-10). This study showed that learning in the medical school is teacher-centered and exam-oriented and lacks academic governance, and the teachers perceived to be authoritarian. These issues are similar in these environments $(7,10,12)$.

A medical school is a habitat whose principal inhabitants are obviously its students for whose education, training, and welfare the institution exists(13). It is for this reason that how students perceive the learning environment is key to those who run and work within the institution. Year V students perceive their environment as more friendly because of the tutorials and modular teaching where they stay in one discipline without having joint classes.

Most students felt the learning environment emphasized factual learning, superfluous teacher-centered learning where lecturers just read through the slides, as well as the scores attained in exams. These sentiments are similar to those in a study in Iran (14) and Sri Lanka (15) but contrast with Abraham et al.'s study in India (16). Al-Hazimi et al. showed in a study that students using a traditional medical curriculum often perceived learning as being too teacher-centered, dogmatic, and overemphasizing "rote memorization" (17). Students 
proposed professional development on teaching methods used by the faculty as a way forward as well as changing to problem-based learning with a more balanced curriculum.

The teachers are perceived as being knowledgeable but lacking in delivery skills; they are perceived to be unavailable, irritable, authoritarian, and having difficulties in interacting with patients and giving feedback to students. A number of studies have highlighted similar issues (16). The reason for this kind of behavior could be because the teachers are overworked (7).

Scheduling problems and tension in class and in clinical areas due to personality issues among faculty members leads to a lack of confidence, problems with cheating, and a lack of interpersonal cohesiveness. Similar issues were elicited by another study(7).Students seemed to suggest that role modeling does not allow them learn empathy because it is not often practiced by their teachers. Increased confidence among seniors has been noticed in studies in Asia (14-16).

Lack of social support during stressful periods with no institutional plans in place and little staff involvement may be due to the increased workload of faculty. Lack of support made students feel neglected and added to the authoritarian nature of the teachers, resulting in some students feeling like their lives were being destroyed. Studies have shown that exam anxiety, a lack of leisure time, and inadequate resources lead to increased stress (18).

This study was conducted 4 weeks to exams. End of year exams exert psychological pressure and may have led students to develop negative perceptions which may have contributed to the findings. The interviewer used guiding questions to avoid bias in the line of questioning, and students were also guided by the questions and allowed open-ended questions.

\section{Conclusion}

The poor perception of the learning environment the DREEM survey elicited was due to educational factors that include governance, students not being supported during stressful times due to a lack of psychosocial support, and lack of long-term investment in university infrastructure.

\section{References}

1. Roff S, McAleer S. What is educational climate? Med Teach. 2001;23(4):333-334.

2. Hutchinson L. Educational environment. BMJ. 2003 ;326 (7393) :810-812.

3. Bakhshialiabad H, Bakhshi G, Hashemi Z, et al. Improving students' learning environment by DREEM: an educational experiment in an Iranian medical sciences university (2011-2016). BMC Med Educ. 2019; 19:397.

4. Kohli V, Dhaliwal U. Medical students' perception of the educational environment in a medical college in India: a cross-sectional study using the Dundee Ready Education Environment Measure questionnaire. J EducEval Health Prof. 2013; 10:5.

5. Roff S, McAleer S, Harden RM, et al. Development and validation of the Dundee Ready Education Environment Measure (DREEM). Med Teach. 1997;19(4):295-299.

6. Aghamolaei T, Fazel I. Medical students' perceptions of the educational environment at an Iranian medical sciences university. BMC Med Educ. 2010;10(1):87.

7. Hasan T, Gupta P. Assessing the learning environment at Jazan Medical School of Saudi Arabia. Med Teach. 2013;35(Suppl 1): S90-96.

8. AlFaris EA, Naeem N, Irfan F, et al. Student-centered curricular elements are associated with a healthier educational environment and lower depressive symptoms in medical students. BMC Med Educ. 2014; 14:192.

9. Koohpayehzadeh J, Hashemi A, SoltaniArabshahi K, et al. Assessing validity and reliability of Dundee Ready Educational Environment Measure (DREEM) in Iran. Med J Islam Repub Iran. 2014; 28:60.

10. Belayachi J, Razine R, Boufars A, et al. Moroccan medical students' perceptions of their educational environment. J EducEval Health Prof. 2015; 12:47

11. Ojuka D, Aseta F, Githambo B, Wambua B. The Medical Education Environment at the University of Nairobi, Kenya: An Assessment with the DREEM Tool. Ann Afr Surg. 2021;18(2): 96-102

12. Andalib MM, Malekzadeh MM, Agharahimi Z, et al. Evaluation of educational environment for medical students of a tertiary pediatric hospital in Tehran, using DREEM questionnaire. Iran J Pediatr. 2015;25(5): e2362.

13. Genn JM. AMEE Medical Education Guide No. 23 (Part 1): Curriculum, environment, climate, quality and change in medical education-a unifying perspective. Med Teach. 2001;23(4):337-344.

14. Taheri M. Students' perceptions of learning environment in Guilan University of Medical Sciences. J Med Educ. 2009;13(4):126-133

15. Lokuhetty MD, Warnakulasuriya SP, Perera RI, et al. Students' perception of the educational environment in a medical faculty with an innovative curriculum in Sri Lanka. Southeast Asian J Med Educ. 2010;4(1):9-16 


\section{MEDICAL STUDENTS' PERCEPTION OF THEIR EDUCATION LEARNING ENVIRONMENT}

16. Abraham R, Ramnarayan K, Vinod P., et al. Students' perceptions of learning environment in an Indian medical school. BMC Med Educ. 2008;8(1):1-5.

17. Al-Hazimi A, Zaini R, Al-Hyiani A, et al. Educational environment in traditional and innovative medical schools: a study in four undergraduate medical schools. Educ Health. 2004;17(2):192-203

18. Sanders AE, Lushington K. Sources of stress for Australian dental students. J Dent Educ. 1999;63(9):68869 